\title{
Diagnostic and Prognostic Power of the First Biometric Measurements and Doppler Examination in Fetal Growth Restriction
}

Semir KÖSE

${ }^{a}$ Clinic of Perinatology, Buca Women Birth and Child Diseases Hospital, İzmir, TURKEY

Received: 01 Jul 2019

Received in revised form: 03 Oct 2019

Accepted: 07 Oct 2019

Available online: 22 Oct 2019

\section{Correspondence:}

Semir KÖSE

Buca Women Birth and

Child Diseases Hospital,

Clinic of Perinatology,

İzmir, TURKEY

semirkose@yahoo.com

\begin{abstract}
Objective: Evaluation of fetal growth constitutes a core component of prenatal care. However, the limited accuracy of the sonographic examination complicates this task. In the present study, we assessed the diagnostic and prognostic power of the first biometric measurements and the three arterial Doppler indices in cases with suspected fetal growth restriction (FGR). Material and Methods: A retrospective, cross-sectional study was conducted between August 2016 and January 2019. Data on suspected FGR cases were obtained from consultations. Three biometric measurements, namely abdominal circumference (AC), estimated fetal weight (EFW), and femur length (FL); three arterial Doppler indices (umbilical, uterine, and middle cerebral) and one combinatory index; the cerebroplacental ratio (CPR) were analyzed to predict cases with neonatal birth weight (NBW) $<10^{\text {th }}$ centile. Results: In a sample of 352 pregnancies diagnosed as FGR, $246(69.9 \%)$ cases reported NBW $<10^{\text {th }}$ centile (true positives). The $\mathrm{AC}<3^{\text {rd }}$ centile had the highest sensitivity (81.9\%), whereas EFW $<3^{\text {rd }}$ centile had the highest specificity $(83.2 \%)$. For each biometric measurement, the addition of any Doppler index resulted in decreased sensitivity but increased specificity. The frequency of cases with at least one Doppler abnormality was significantly higher in true-positive cases than in false-positive cases ( $36.9 \%$ vs. $22.6 \%$, respectively; $\mathrm{p}=0.008)$. In cases with late-onset FGR, $\mathrm{CPR}<5^{\text {th }}$ centile was associated with an increased risk of admission to neonatal intensive care unit (NICU) (odds ratio [OR]: 6.42; 95\% confidence interval [CI]: 2.24-18.40; $\mathrm{p}=0.001$ ). Conclusion: A high sensitivity was associated with the first biometric measurements for detecting FGR. The CPR $<5$ th centile could be useful in predicting cesarean delivery for fetal distress and NICU admissions in cases with late-onset FGR.
\end{abstract}

Keywords: Cerebroplacental ratio; fetal growth restriction; fetal distress; management of pregnancy; small for gestational age

ne of the main components of prenatal care is to assess fetal development using several parameters. Evaluation of fetal growth relies mainly on sonographic biometric measurements of the fetus and estimation of percentile values of these measurements. ${ }^{1,2}$ When the percentile values fall below the critical levels, a "small fetus" is suspected and a detailed further examination of the pregnancy with the help of Doppler modality comes into question. ${ }^{3}$

In our national antenatal care practice, the otherwise healthy pregnant women are invited to routine monthly visits. ${ }^{4}$ In this surveillance model, the $36^{\text {th }}$ week's gestation serves as the critical stage for checking the fetal growth.

Small for gestational age (SGA) fetus and fetal growth restriction (FGR) are two radically different terms that are commonly used interchangeably. ${ }^{3}$ Based on their main concepts, the clinician uses the term "FGR" when there 
is a severe restriction and/or a manifestation of Doppler evidence of placental insufficiency and prefers to use the term "SGA" when the restriction is moderate (between $3^{\text {rd }}$ and $10^{\text {th }}$ centiles) or when no Doppler abnormalities are found. ${ }^{3,5}$ The Doppler evaluation of three arterial spaces (umbilical, uterine, and middle cerebral) and one combination index, and the cerebroplacental ratio (CPR) are accepted as the standard for investigating a small fetus. ${ }^{3,5}$

Although FGR should be viewed as a process rather than as a point event and the diagnosis should be on the basis of serial ultrasound evaluations, the first biometric and Doppler examination is critical both as the first step to the definitive diagnosis and in scheduling the pregnancy follow-up. ${ }^{2}$

In the present study, we present the hypothesis that the percentile values of three biometric measurements, namely, abdominal circumference (AC), estimated the fetal weight (EFW), and femur length (FL), have a high correlation with the neonatal birth weight (NBW). The second hypothesis was that as the Doppler evaluation reflects the hemodynamic status of the fetus, adding one of the three arterial Doppler indices (umbilical, uterine, or middle cerebral) or one combination index, CPR could be used to increase the specificity of FGR diagnosis (selecting the actual FGR cases) and could be useful in predicting the distress-prone fetuses and neonatal intensive care unit (NICU) admissions.

\section{MATERIAL AND METHODS}

This cross-sectional study was conducted using the data obtained from the consultations for FGR suspicion at the Buca Maternity Hospital, Turkey, during the period from August 2016 to January 2019. Only cases that were referred for FGR, small AC, BPD, and FL discrepancy or SGA were included in the sample.

The inclusion criteria were singleton pregnancies that were above the $24^{\text {th }}$ weeks of gestation at first examination, confirmation of the SGA/FGR by the perinatologist, complete set of measurements of fetal biometry and the three arterial
Doppler indices, and complete information on the delivery and the newborn outcomes. The exclusion criteria were any serologic or sonographic sign of infectious etiology, placenta previa, single umbilical artery, FGR with comorbidities (gestational diabetes mellitus and preeclampsia at the time of examination), maternal systemic diseases (chronic hypertension, type 1 diabetes mellitus, and autoimmune disorders), incomplete information on the studied variables, and chromosomal and structural anomalies.

During the study period, a total of 498 pregnant women were referred for confirmation and further evaluation of FGR. Of these, 146 pregnancies were excluded for various reasons: in 92 cases (63.0\%), true gestational age could not be estimated (not remembering the last menstrual date and not having a documentation of cranium-rump length (CRL) measurement); 22 cases (15.1\%) were complicated with gestational diabetes mellitus (regulated with diet or insulin); 9 cases (6.2\%) were diagnosed or suspected with rupture of the membrane at examination; in 8 cases (5.5\%), delivery occurred at other hospitals without available outcomes; 5 (3.4\%) fetuses had various signs of chromosomal or syndromic genetic disorders; 3 cases (2.1\%) reported suspicious viral serologies; 3 (2.1\%) pregnancies were associated with maternal arterial hypertension at diagnosis; in 2 cases (1.4\%), the fetal head was engaged deeply at the pelvis preventing middle cerebral artery (MCA) measurements; and 2 cases (1.4\%) had placenta previa.

All examinations were performed by a perinatology specialist (S.K.) and stored on the ultrasound machine's hard drive. All measurements were performed using a Samsung SonoAce R7 (Samsung Medison; Seoul, South Korea) ultrasound machine.

To analyze the degree of growth pathology for fetal size parameters, a formula transforming the measurements in days to a percent deviation (\%DV) was applied. This \%Dev approach was used for statistical analysis and interpretation of these size parameters as a measure of growth potential realization at a time point by quantifying the growth pathology. ${ }^{6}$ 
$\% \operatorname{Dev}=\left(\frac{\text { measured parameter-predicted parameter }}{\text { predicted parameter })}\right) \times 100^{6}$

The arterial Doppler measurement techniques were the same as described by the ISUOG guidelines. ${ }^{7}$ The pulsatility index (PI) was selected for statistical analysis owing to its wide preference in the related literature. ${ }^{5,7,8}$ The percentiles of arterial measurements were calculated according to the widely accepted nomogram reference studies: the nomogram presented by Gomez et al. was used for mean uterine artery (Ut A) PI, the reference ranges of Acharya et al. were used for umbilical artery (UA) PI, and the study of Ebbing et al. was used for the MCA PI and the CPR. ${ }^{9-11}$

The FGR was defined as EFW $<10^{\text {th }}$ centile based on the ultrasonographic measurements of fetal biparietal diameter (BPD), head circumference (HC), AC, and femur length (FL) (Hadlock2 ) or $\mathrm{AC}<10^{\text {th }}$ centile with an accompanying Doppler abnormality. ${ }^{8,12,13}$ The $32^{\text {nd }}$ week of gestation served as the cut-off point for the classification of early- versus late-onset FGR. ${ }^{13}$ The neonatal birth weight (NBW) was categorized according to the gestational age during delivery and the gender of the newborn.

The clinical decisions on the FGR-diagnosed pregnancies were made based on two widely accepted follow-up models-the predictable progression approach described by Turan et al. and the gestational age at diagnosis (GAAD)-based followup model described by Figueras et al., along with individual case characteristics, the NICU facilities of the institution, and when required the preferences of the couples. ${ }^{3,14}$

The study was approved by the Health Sciences University Tepecik Training and Education Hospital Clinical Trials Ethical Committee (approval number: 2019/2-16, decision date: $13 / 02 / 2019)$. The study was conducted in accordance with the ethical principles of the Helsinki declaration.

\section{STATISTICAL ANALYSIS}

The results were presented as the mean \pm standard deviation for normally distributed variables, as the median (range) for non-normally distributed vari- ables and as frequencies for categorical variables. Student's t-test was used to compare the independent group means, and a chi-square test was used to compare the categorical variables. For non-normally distributed variables and ordinal variables, comparisons were performed using the KruskalWallis test and Dunn correction, and the MannWhitney $U$ test was performed to test the significance of pairwise differences to adjust for multiple comparisons. Frequencies were compared between the groups with chi-square analysis (when two groups were tested) and with multi-box chisquare analysis (when four groups were tested). To determine the predictors of follow-up time, a linear regression analysis was first conducted, followed by multiple linear regression to study a predictive model. The Cox regression analysis requires a censored variable to be conducted. The censored variable was selected as "delivery during the first seven days" status to assess the power of the clinical and Doppler parameters as predictors of the follow-up time variable in the NBW $<10^{\text {th }}$ centile group. Data were analyzed using the SPSS software (version 22; Chicago, Illinois, USA). A p-value less than 0.05 was considered statistically significant.

\section{RESULTS}

\section{STUDY GROUP}

A sample of 352 pregnancies was analyzed. The median maternal age was 26 years (17-45 years) and the median GAAD was 36 weeks $(w)$ four days (d) (25w3d-42w0d) in the cohort. The number and frequencies of the nulliparous and parous women were 165 (46.9\%) and 187 (53.1\%), respectively. The median EFW at first biometry was 2200 (700$3050)$ grams. Of all pregnancies, 64 (18.2\%) women were active smokers. Fetal gender at sonographic examination was noted as 190 (53.9\%) females, 160 (45.5\%) males, and $2(0.6 \%)$ ambiguous genitalia. These observations were confirmed postnatally. Oligohydramnios was detected in 71 cases $(20.2 \%)$ at first examination.

The number and frequency of the pregnancies with an NBW $<10^{\text {th }}$ centile was $246(69.9 \%)$, and $106(30.1 \%)$ pregnancies had an NBW $\geq 10^{\text {th }}$ centile (Table 1). 


\begin{tabular}{|lccc|}
\hline \multicolumn{4}{|c|}{ TABLE 1: Comparison of the true and false positive groups according to their main obstetric and clinical properties. } \\
\hline & Neonatal birth weight $<10^{\text {th }}$ centile & Neonatal birth weight $\geq 10^{\text {th }}$ centile \\
Characteristics & $n: 246$ & $n: 106$ & $\mathbf{p}$ \\
\hline Maternal age median (range) & $26.0(17-45)$ & $27.5(18-40)$ & 0.358 \\
\hline Gestational age at diagnosis days median (range) & $257(178-280)$ & $252(182-283)$ & 0.004 \\
\hline Gestational age at diagnosis weeks median (range) & 36 w5d (25w3d-40w0d) & 36 w0d (26w0d-42w0d) & 0.005 \\
\hline Gestational age at delivery days median (range) & $269(208-295)$ & $271(224-289)$ & 0.510 \\
\hline Nulliparity \% & 56.4 & 37.7 & $<0.0001$ \\
\hline Gender (Female/male) & $137(55.6 \%) / 109(44.4 \%)$ & $56(52.8 \%) / 50(47.2 \%)$ & 0.549 \\
\hline Smoking \% & $46(18.7 \%)$ & $18(16.9 \%)$ & 0.701 \\
\hline Oligohydramnios \% & 22.1 & 17.9 & 0.302 \\
\hline Median estimated fetal weight at diagnosis grams (range) & $2200(700-2900)$ & $2284(720-3050)$ & 0.139 \\
\hline Median neonatal birth weight grams (range) & $2550(940-3050)$ & $3052(1680-3800)$ & $<0.0001$ \\
\hline Delivery route (vaginal/cesarean) & $148(60.2 \%) / 98(39.8 \%)$ & $82(77.3 \%) / 22(20.7 \%)$ & 0.027 \\
\hline NICU admission & $49(19.9 \%)$ & $1(0,9 \%)$ & $<0.0001$ \\
\hline Number and frequency of cases with CPR $<5^{\text {th }}$ centile at first examination & $48(19.5 \%)$ & $8(7.5 \%)$ & 0.004 \\
\hline Number of cases with at least one Doppler abnormality & $91(36.9 \%)$ & $24(22.6 \%)$ & 0.008 \\
\hline Follow up time in days median (range) & $12(0-101)$ & $18(0-100)$ & 0.003 \\
\hline
\end{tabular}

NICU: Neonatal intensive care unit; CPR: Cerebroplacental ratio.

The percentile distribution of cases with NBW $\geq 10^{\text {th }}$ centile was as followed: 75 cases $(70.8 \%)$ were from 10 to $20^{\text {th }}$ centiles, 27 cases ( $\left.25.4 \%\right)$ were from 21 to $50^{\text {th }}$ centiles, and 4 cases (3.8\%) were from 51 to $99^{\text {th }}$ centiles.

The NBW $<10^{\text {th }}$ centile cases were divided into four categories according to their GAAD: $<30$ weeks, 30w1d-33w6d, 34w0d-36w6d, and $\geq 37^{\text {th }}$ weeks. The main characteristics of these categories are presented in Table 2.

The diagnostic accuracy was the highest in cases with early-onset FGR: 14/17 (82.3\%) of cases that were consulted at or before 30 weeks' gestation were $<10^{\text {th }}$ centile at birth. The remaining three cases were at the border of the SGA cut-off level: 11,13 , and $16 \%$.

Preeclampsia was diagnosed in 5/246 (2.03\%) women; 2 cases were in the $<30$ week GAAD group, and the remaining three cases were in the late-onset FGR group. Two cases $(0.8 \%)$ of placental abruption were observed in the NBW $<10^{\text {th }}$ centile group; both women were smokers.

The only surveyed postnatal death (1/246; $0.4 \%)$ occurred in the 6th month in a case from 30w1d$33 w 6 d$ GAAD category. No case of intrauterine fetal death was reported in the study group.
In the SGA group, the smoking habit was associated with increased risk of cesarean delivery for fetal distress indication (OR: 3.0; 95\% CI: 1.07-8.37; $\mathrm{p}=0.033$ ).

Oligohydramnios at the diagnosis was found to be a risk factor for NICU admission in the SGA group (OR: 5.4; 95\% CI: 1.82-15.97; $\mathrm{p}=0.003$ ).

\section{ANALYSIS OF BIOMETRIC MEASUREMENTS}

The frequency of cases presented with AC value of $<3^{\text {rd }}$ centile was higher in the NBW $<10^{\text {th }}$ centile group: $80.9 \%$ vs. $57.3 \%(\mathrm{p}<0.0001)$. The frequency of cases presented with FL value of $<3^{\text {rd }}$ centile was higher in the NBW $<10^{\text {th }}$ centile group: $51.8 \%$ vs. $18.2 \%(\mathrm{p}<0.0001)$. The $\mathrm{AC}<3^{\text {rd }}$ centile reported the highest sensitivity $(81.9 \%)$ for the diagnosis of NBW $<10^{\text {th }}$ centile, whereas EFW $<3^{\text {rd }}$ centile reported the highest specificity $(83.2 \%)$. The highest specificity (100\%) and PPV (100\%) were obtained with the combination of $F L<3^{\text {rd }}$ centile and UA PI $>95^{\text {th }}$ centile. None of the cases with FL $<3^{\text {rd }}$ centile and UA PI $>95^{\text {th }}$ centile combination $(n=36)$ were above the $10^{\text {th }}$ centile at birth. While reaching a high specificity (92.2\%) and PPV (87.8\%), the combination of EFW $<3^{\text {rd }}$ centile and UA $>95^{\text {th }}$ centile resulted in a false-negative diagnosis in 143 (58.1\%) cases. At the time of diagnosis, either the 
TABLE 2: Presentation of the cases with neonatal birth weight less than $10^{\text {th }}$ percentile according to the gestational age at diagnosis.

\begin{tabular}{|c|c|c|c|c|c|}
\hline Characteristics & $\begin{array}{c}\geq 37 w 0 d \\
n: 92(37.4 \%)\end{array}$ & $\begin{array}{l}\text { 34w0d-36w6d } \\
\text { n:105 (42.7\%) }\end{array}$ & $\begin{array}{c}30 w 0 d-33 w 6 d \\
n: 35(14.2 \%)\end{array}$ & $\begin{array}{c}<30 \mathrm{w} 0 \mathrm{~d} \\
\mathrm{n}: 14(5.7 \%)\end{array}$ & $p$ \\
\hline Maternal age median (range) & $25(18-38)$ & $26(17-41)$ & $27(17-39)$ & $26(21-45)$ & 0.138 \\
\hline Nulliparity (\%) & $60.8 \%$ & $56.2 \%$ & $52.0 \%$ & $55.0 \%$ & 0.289 \\
\hline Smoking (\%) & $21.5 \%$ & $21.3 \%$ & $21.4 \%$ & $18.2 \%$ & 0.994 \\
\hline Severe FGR $\left(<3^{\text {rd }}\right.$ centile) $(\%)$ & $40.2 \%$ & $32.1 \%$ & $48.6 \%$ & $26.7 \%$ & 0.307 \\
\hline Follow up duration days median (range) & $5(0-27)$ & $16(0-39)$ & $36(0-74)$ & $48(2-101)$ & $<0.0001$ \\
\hline \multicolumn{6}{|l|}{ Doppler findings \% } \\
\hline UA PI $>95^{\text {th }}$ centile & $23(25.0 \%)$ & $32(30.5 \%)$ & $15(42.9 \%)$ & $7(50.0 \%)$ & 0.024 \\
\hline MCA PI $<5^{\text {th }}$ centile & $17(18.5 \%)$ & $21(20.0 \%)$ & $8(22.8)$ & $2(14.3 \%)$ & 0.951 \\
\hline $\mathrm{CPR}<5^{\text {th }}$ centile & $12(13.0 \%)$ & $18(17.1 \%)$ & $6(17.1 \%)$ & $2(14.3 \%)$ & 0.466 \\
\hline Mean Ut A PI >95 $5^{\text {th }}$ centile & $17(18.5 \%)$ & $22(20.9 \%)$ & $15(42.8 \%)$ & $8(57.1 \%)$ & 0.001 \\
\hline AEDF-REDF-DV absent of a wave & $1(1.1 \%)$ & $2(1.9 \%)$ & $2(5.7 \%)$ & $1(7.1 \%)$ & 0.019 \\
\hline Decisions & & & & & $<0.0001$ \\
\hline Immediate delivery & $1(1.1 \%)$ & $6(5.7 \%)$ & $2(5.7 \%)$ & $0(0.0 \%)$ & \\
\hline Induction of labor & $33(35.9 \%)$ & $12(11.4 \%)$ & $0(0.0 \%)$ & $0(0.0 \%)$ & \\
\hline Follow up & $58(63.0 \%)$ & $87(82.8 \%)$ & $33(94.3 \%)$ & $14(100.0 \%)$ & \\
\hline Cesarean delivery for fetal distress & $26(28.2 \%)$ & $23(21.9 \%)$ & $14(40.0 \%)$ & $4(28.6 \%)$ & 0.053 \\
\hline NICU admission & $9(9.8 \%)$ & $16(15.2 \%)$ & $17(48.6 \%)$ & $7(50.0 \%)$ & $<0.0001$ \\
\hline
\end{tabular}

FGR: Fetal growth restriction; UA PI: Umbilical artery pulsatility index; MCA PI: Middle cerebral artery pulsatility index; CPR: Cerebroplacental ratio; UtA PI: Uterine artery pulsatility index; AEDF: Absent end-diastolic flow; REDF: Reverse end-diastolic flow; DV: Ductus venosus; NICU: Neonatal intensive care unit.

EFW was above the $3^{\text {rd }}$ centile or the UA PI was not above the $95^{\text {th }}$ centile in $58.1 \%$ of NBW $<10^{\text {th }}$ centile cases (Table 3).

None of the cases with EFW $<3^{\text {rd }}$ centile and mean UtA PI $>95^{\text {th }}$ centile was above the $10^{\text {th }}$ centile at delivery, indicating a $100 \%$ specificity, and $103(29.2 \%)$ cases with EFW $>3^{\text {rd }}$ centile and/or mean UtA PI $<95^{\text {th }}$ centile were above the 10 th centile at delivery.

For each biometric measurement, addition of any Doppler indices resulted in decreased sensitivity but increased specificity (Table 3 ).

In the FGR group, the frequency of cases with $\mathrm{FL}<5^{\text {th }}$ centile was not significantly higher in the smoking pregnant women than in non-smokers: $48.8 \%$ vs. $38.9 \%(\mathrm{p}=0.228)$.

The cranial size parameters, i.e., BPD and $\mathrm{HC} \%$ deviations were significantly higher in female fetuses than in the male fetuses: $-6.6(-20$, $+12) \%$ vs. $-4.8(-18,+11) \%$; $\mathrm{p}<0.0001$ and $-4.2(-21$, $+13) \%$ vs. $-1.7(-14,+12) \%$; $\mathrm{p}<0.0001$, respectively. The FL and AC \%Dev were not significantly different between the two genders: $-6.6(-20,+3) \%$ in females vs. $-5.5(-19,+3) \%$ in males: $p=0.643$ and -
$9.7(-22,+3) \%$ in females vs. $-10.1(-18,+2) \%$ in males: $\mathrm{p}=0.572$, respectively. The only significant correlation was found between the $\mathrm{AC} \% \mathrm{Dev}$ and the follow-up time: correlation coefficient $(\mathrm{CC})=0.425, \mathrm{p}<0.0001$.

\section{ANALYSIS OF DOPPLER INDICES}

The number and frequency of cases with at least one Doppler abnormality were significantly higher in true-positive cases (NBW $<10^{\text {th }}$ centile) than in false-positive cases (NBW $\geq 10^{\text {th }}$ centile): 91 (36.9\%) vs. 24 (22.6\%), respectively; $\mathrm{p}=0.008$ (Table 1 ).

In the $<30 \mathrm{w}$ GAAD group, $\mathrm{CPR}<5^{\text {th }}$ centile was detected in two cases (14.3\%; Table 2). In the 30w1d-33w6d GAAD category, the median followup was significantly lower in cases presented with MCA $<5^{\text {th }}$ centile than in cases with MCA $\geq 5^{\text {th }}$ centile at first examination; 4 (3-30) days vs. 37 (1153) days; ( $\mathrm{p}=0.003)$.

In the $34 w 0 d-36 w 6 d$ GAAD category, Doppler findings suggested that six cases $(5.7 \%)$ required emergency cesarean delivery for asphyxia (Table 2), whereas labor was induced in 21 cases $(20.0 \%)$ based on the findings at diagnosis. In this 


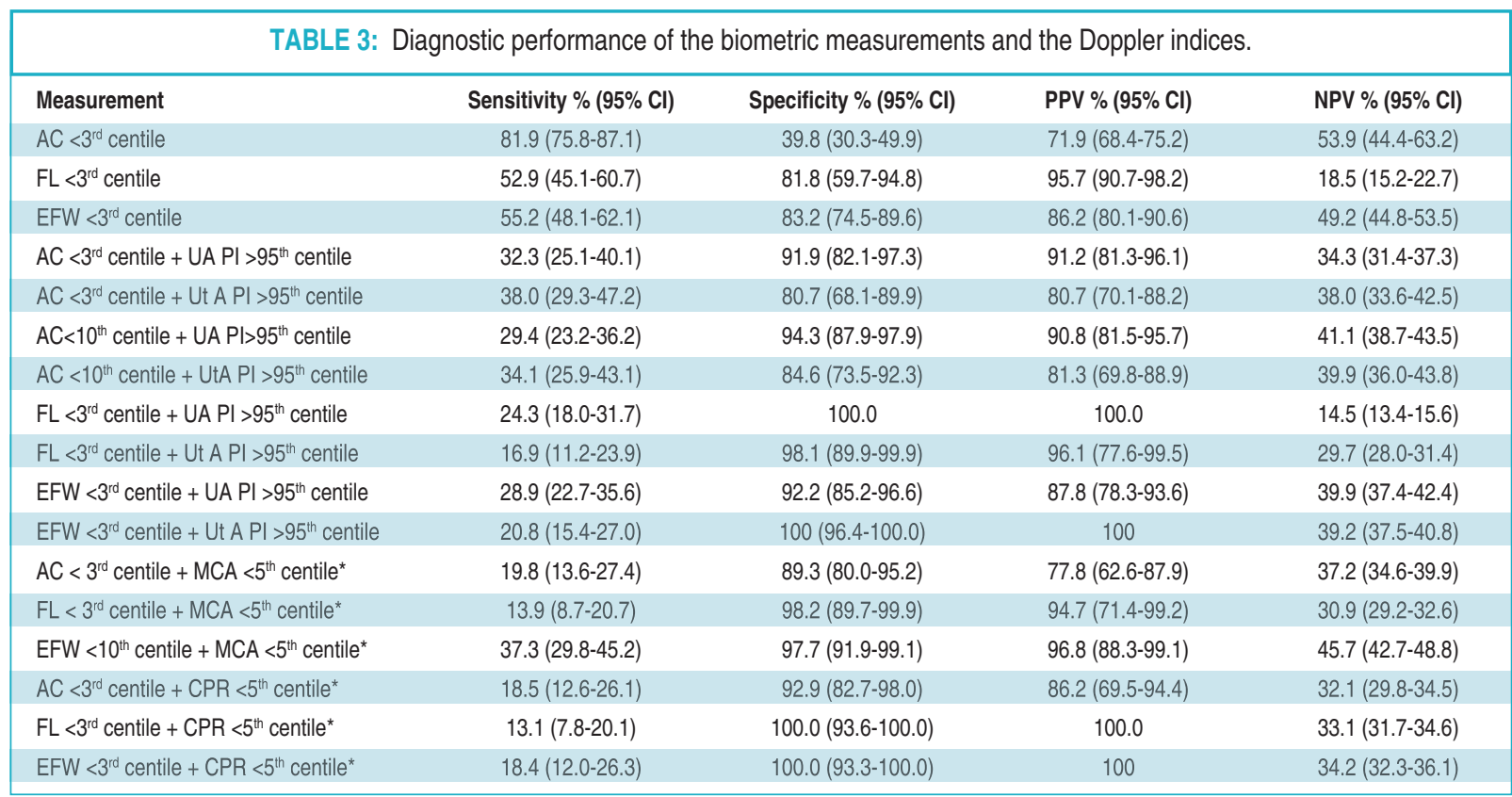

${ }^{\star}$ These combinations were evaluated only for their diagnostic performance in late-onset FGR

PPV: Positive predictive value; NPV: Negative predictive value; AC: Abdominal circumference; FL: Femur length; EFW: Estimated fetal weight; CPR: Cerebroplacental ratio.

gestational age category, the median CPR was not significantly different between true-positive and false-positive cases ( 1.89 vs. $1.97 ; \mathrm{p}=0.068$ ). The frequency of the cases presented with MCA $<5^{\text {th }}$ centile was higher in the NBW $<10^{\text {th }}$ centile group; $21 \%$ vs. $8.8 \%(\mathrm{p}=0.014)$.

In the $\geq 37^{\text {th }}$ week GAAD group, $1(1.1 \%)$ of the cases required emergency cesarean delivery for AEDF (Table 1) and labor was induced in 33 cases (35.9\%) on the basis of findings at diagnosis. The number and ratio of cases that required NICU admission were higher in the group induced to labor than in the follow-up group: $6 / 33(66.6 \%)$ vs. $2 / 58$ $(3.4 \%)(\mathrm{p}=0.031)$. The median NBW was higher in the group with induced labor than in the followup group: 2495 grams (1980-3000) vs. 2120 (20153050) $(\mathrm{p}<0.0001)$.

When we look at the NBW $<10^{\text {th }}$ centile group, the mean CPR value was higher in the vaginal delivery group than in the cesarean delivery for fetal distress indication group $(1.99 \pm 0.71$ vs. 1.54 $\pm 0.63 ; \mathrm{p}=0.009$ ). The mean UA PI was also higher in cases that required cesarean delivery for fetal distress than in cases that underwent vaginal delivery $(1.13 \pm 0.44$ vs. $0.95 \pm 0.17 ; \mathrm{p}=0.019)$. The difference between the mean UA PI could not reach a statistical significance $(1.01 \pm 0.40$ vs. $0.82 \pm 0.31 ; \mathrm{p}=0.068$ ).

The frequency of FGR cases presented with UA PI $>95^{\text {th }}$ centile was higher in the early-onset FGR group than in the late-onset FGR group ( $46.8 \%$ vs. $28.9 \%, \mathrm{p}=0.041$ ). When we divided the FGR cases as $<37$ weeks' gestation and $\geq 37^{\text {th }}$ week at diagnosis, the frequencies of cases with UA PI $>95^{\text {th }}$ centile were not significantly different ( $35.1 \%$ vs. $25.0 \% ; \mathrm{p}=0.099$ ).

The frequencies of FGR cases presented with MCA $<5^{\text {th }}$ centile were not significantly different between the early- and late-onset cases $(20.2 \%$ vs. $15.8 \% ; \mathrm{p}=0.314$ ). The frequencies of cases presented with $\mathrm{MCA}<5^{\text {th }}$ centile were not significantly different between the cases diagnosed before and after the $37^{\text {th }}$ gestational weeks ( $18.5 \%$ vs. $20.1 \%$; $\mathrm{p}=0.751$ ).

One of the newborns with NBW $\geq 10^{\text {th }}$ centile required NICU admission. This case was $32 \mathrm{w} 1 \mathrm{~d}$ and $\mathrm{CPR}<5^{\text {th }}$ centile at the first examination and the indication for the cesarean delivery was fetal distress documented by cardiotocography (CTG). The other seven cases with $\mathrm{NBW} \geq 10^{\text {th }}$ centile and $\mathrm{CPR}<5^{\text {th }}$ centile did not require NICU admission (Table 1). 
A multiple linear regression model $\left(\mathrm{R}^{2}=0.69\right)$ was used to identify independent predictors of the follow-up time in cases with $\mathrm{NBW}<10^{\text {th }}$ centile. The GAAD (Beta -, 737; $\mathrm{p}<0.0001$ ), the mean UtA PI (Beta -, 307; $\mathrm{p}<0.0001$ ), and MCA PI (Beta, 192; $\mathrm{p}<0.0001$ ) were strong predictors of follow-up time. The EFW (Beta, 227; p=0.059) and UA PI (Beta -, 110; $\mathrm{p}=0.171$ ) could not add to the multiple linear regression model.

The power of these clinical and Doppler parameters was assessed using the Cox regression analysis to predict the need for delivery during the first seven days. The GAAD (H: 1.05, 95\% CI: 1.031.09; $\mathrm{p}<0.0001)$, the MCA PI $<5^{\text {th }}$ centile $(\mathrm{H}: 0.29$, 95\% CI: 0.14-0.59, $\mathrm{p}=0.001$ ), the mean UtA PI $>95^{\text {th }}$ centile (H: 0.39, 95\% CI: 0.19-0.79; $\mathrm{p}=0.009$ ), and UA PI $>95^{\text {th }}$ centile $(\mathrm{H}: 0.44,95 \%$ CI: 0.21-0.96; $\mathrm{p}=0.039$ ) were predictors of follow-up time censored by "delivery during the first seven days" status in the NBW $<10^{\text {th }}$ centile group.

The mean UtA PI was significantly lower in pregnancies with female fetuses than in those with male fetuses: 0.76 (0.41-2.00) vs. 0.83 (0.46-2.10), respectively $(\mathrm{p}=0.043)$. The MCA PI was significantly higher in pregnancies with female fetuses than in those with male fetuses: 1.86 (0.81-3.56) vs. 1.70 (0.81-3.56), respectively $(\mathrm{p}=0.043)$.

\section{DISCUSSION}

The primary finding of the present study was that the first biometric measurements had a high sensitivity (69.9\%) for detecting the fetuses that were NBW $<10^{\text {th }}$ centile. The remaining "false positives" were at the border of the cut-off level; $70.8 \%$ of cases were between the $10^{\text {th }}$ and $20^{\text {th }}$ centiles. From another perspective, this simple finding emphasized the notion of FGR as a diagnosis of surveillance and the power of a single evaluation was limited both in diagnostic and prognostic accuracy. ${ }^{1-3}$

In the cohort, the median GAAD was $36 \mathrm{w} 4 \mathrm{~d}$ (25w3d-42w0d). In our current national pregnancy care model, suspicion on the fetal growth appeared to emerge at around the $36^{\text {th }}$ week. The fetal growth velocity is non-monotonic and asynchro- nous with different acceleration periods for each biometric measurement. ${ }^{15,16}$ The AC has been reported to have two acceleration periods: first at $16^{\text {th }}$ week followed by in early third trimester (27-31 weeks). ${ }^{15}$ The velocity of long bones (including FL) continue to slow and EFW velocity continues to accelerate peaking at 35 weeks of gestation. ${ }^{15}$ These growth rhythms explain the fact that small fetuses start to reveal themselves at 35 to $36^{\text {th }}$ weeks of gestation.

The AC measurement seemed to reflect an allor-none phenomenon. Of all the SGA fetuses, 80.9\% were diagnosed with an $\mathrm{AC}<3^{\text {rd }}$ centile. This finding suggested that when the growth restriction reached a sonographically detectable level, the AC was already confined to its lower limits. Decreased liver size, reduced glycogen storage, and depleted adipose tissue in the abdominal region are the causes of the lower AC measurements in FGR cases and if the $\mathrm{AC}$ is within the normal range, the presence of FGR is unlikely. ${ }^{5,17}$ When the biometric measurements were evaluated in isolation, $\mathrm{AC}$ was the most sensitive (81.9\%) parameter for detecting FGR (Table 3); this finding was in accordance with the related literature. ${ }^{18,19}$

The number and frequency of cases with at least one Doppler abnormality were significantly higher in true-positive cases than in false-positive cases (Table 1). This finding indicated three important facts about fetal growth abnormalities. First, the true SGA/FGR cases presented more frequently with a Doppler abnormality and this characteristic could be used to schedule the surveillance. ${ }^{7,12}$ Second, the fetal growth abnormalities are a spectrum and a continuum rather than an all-or-none phenomenon. A significant number of false-positive cases in the present study were also "growth restricted" that "could not reach their biologic/genetic growth potential." Despite demonstrating some biometric and circulatory Doppler findings of being restricted, they did not fall below a cut-off ( $10^{\text {th }}$ centile). Moreover, this category presents a great challenge for Obstetrics and Perinatology because we have started to investigate the fetal growth velocity and subtle Doppler signs of impaired placental func- 
tion rather than waiting for a fall below a rigid cut-off to deal with a fetus as growth restricted. ${ }^{20,21}$ Third, as not all SGA/FGR cases presented with a Doppler abnormality at the time of diagnosis. Doppler findings could not be used to exclude a growth restriction or a relative placental insufficiency.

The PORTO study paved the way for and the Delphi procedure formalized the concept of using the Doppler indices as diagnostic criteria for FGR. ${ }^{8,13}$ If the biometric measurements were severely restricted $\left(\mathrm{EFW}>3^{\text {rd }}\right.$ centile and/or $\mathrm{AC}>3^{\text {rd }}$ centile), they were accepted as sufficient findings; however, if the biometric measurements were not at this level, an additional Doppler index from one of the three arterial fields was required for the diagnosis of FGR. ${ }^{3,8,13}$ In the present study, the addition of each arterial Doppler index increased the specificity and the PPV while reducing the sensitivity (Table 3). Doppler findings at the first diagnostic examination should be used to schedule the following visit. In the absence of a Doppler abnormality, the second ultrasound examination was planned 2 weeks later in the 24 to 37 th week as advised in the related literature. ${ }^{3,12,14}$

Currently, CPR is one of the most debated research subjects of fetal growth surveillance..$^{22,23}$ In the present study, CPR was a strong factor for improving the specificities of the biometric measurements (Table 3) and a powerful predictor of the follow-up time in FGR/SGA cases and NICU admissions (Table 4).
Adding the $C P R<5^{\text {th }}$ centile finding to the $\mathrm{EFW}<3^{\text {rd }}$ centile measurement increased the sensitivity and PPV to a $100 \%$ level (Table 3 ). This fact is the main rationale for the current FGR followup models. ${ }^{3,5,21,23,24}$ As biometric measurements are geometrical parameters, they could reflect only the volumetric structure of the fetus and could not discriminate between constitutional smallness- and placental insufficiency-related pathologic growth. As a combination Doppler index, CPR demonstrates the hemodynamic status of the fetus better than the UA PI or MCA PI alone and therefore has the potential to reveal the compensatory changes and enable the selection and close surveillance of fetuses with the actual risk of perinatal hypoxia even if the EFW $>10^{\text {th }}$ centile..$^{23-26}$

The CPR $<5^{\text {th }}$ centile was associated with an increased risk of delivery indication during the first seven days (H: 0.17, 95\% CI: 0.06-0.45; $<<0.0001$ ). In late-onset SGA/FGR fetuses a $\mathrm{CPR}<5^{\text {th }}$ centile was associated with an increased risk of NICU admission (OR: 6.42; 95\% CI: 2.24-18.40; $\mathrm{p}=0.001$ ).

The main problems associated with the clinical use of CPR are the reference ranges and the cutoff points to describe a positive finding. ${ }^{5}$ Several definitions of abnormal CPR have been reported: ratio $<1.00$, ratio $<1.08,<5^{\text {th }}$ centile for $\mathrm{GA}$, and even multiple of median $(\mathrm{MoM})<0.67 . .^{5,23}$ Considering the reference range of Ebbing et al. or Baschat et al., it was associated with a significantly different number of cases that were classified as positive or negative: $21.2 \%$ vs. $11.1 \%$ ( $\mathrm{p}=0.005$; Table 4 ). ${ }^{11,26}$

\begin{tabular}{|c|c|c|c|c|c|c|}
\hline \multirow[b]{4}{*}{ Outcomes } & \multirow{3}{*}{\multicolumn{2}{|c|}{$\begin{array}{l}\text { Late-onset SGA cases } \\
\qquad \mathrm{n}: 208 \\
\text { rence range from Ebbing et al. }\end{array}$}} & \multicolumn{4}{|c|}{ Late-onset SGA cases } \\
\hline & & & & & & \\
\hline & & & & Reference ranges & rom Baschat et al. & \\
\hline & $\begin{array}{c}\text { CPR }<5^{\text {th }} \text { centile } \\
n: 44(21.2 \%)\end{array}$ & $\begin{array}{c}\mathrm{CPR} \geq 5^{\text {th }} \text { centile } \\
\text { n: } 164(68.8 \%)\end{array}$ & $p$ & $\begin{array}{c}\text { CPR }<5^{\text {th }} \text { centile } \\
\text { n:23 }(11.1 \%)\end{array}$ & $\begin{array}{c}\mathrm{CPR} \geq 5^{\text {th }} \text { centile } \\
\mathrm{n}: 185(88.9 \%)\end{array}$ & $p$ \\
\hline Follow up time in days median (range) & $10(0-33)$ & $16(0-53)$ & 0.011 & $8(0-30)$ & $15(0-53)$ & 0.010 \\
\hline Cesarean delivery for fetal distress $n(\%)$ & $24 / 44$ & $32 / 164$ & $<0.0001$ & $16 / 23$ & $40 / 185$ & $<0.0001$ \\
\hline Cesarean delivery for other obstetric indications & $8 / 44$ & $26 / 164$ & 0.984 & $2 / 23$ & $36 / 185$ & 0.207 \\
\hline Uncomplicated vaginal delivery $\mathrm{n}(\%)$ & $12 / 44$ & $106 / 164$ & $<0.0001$ & $5 / 23$ & $113 / 185$ & 0.0003 \\
\hline NICU admission $n(\%)$ & $16 / 44$ & $11 / 164$ & $<0.0001$ & $13 / 23$ & $14 / 185$ & $<0.0001$ \\
\hline
\end{tabular}

SGA: Small for gestational age; NICU: Neonatal intensive care unit; CPR: Cerebroplacental ratio. 
Moreover, this fact was reported by Oros et al. and should be considered both in research designs and clinical practices. ${ }^{22}$

In our study, one case with abnormal CPR and $\mathrm{NBW} \geq 10^{\text {th }}$ centile required admission to NICU (Table 1). As it was associated with adverse perinatal outcomes, three national guidelines recommend delivery at 37 weeks when abnormal CPR/MCA findings were detected in cases with late-onset SGA. ${ }^{20}$ With the growing literature on suboptimally grown fetuses $\left(10^{\text {th }}-50^{\text {th }}\right.$ centiles $)$ and the high frequency of Doppler abnormalities in this group (Table 1), this recommendation started an interesting discussion on whether suboptimally grown fetuses should also be screened for MCA/CPR abnormalities. ${ }^{21,25}$

FGR is the most common cause of intrapartum asphyxia and is one of the most prominent clinical concerns whether the small fetus would develop distress during labor. ${ }^{5,21}$ The frequency of fetal distress increased in cases with $\leq 36 \mathrm{~h}$ of follow-up than in cases with $>36 \mathrm{~h}$ of follow-up $(28.0 \%$ vs. $11.4 \% ; \mathrm{p}<0.0001)$. It was clear evidence for the sensitivity of Doppler evaluation for detecting impaired fetoplacental perfusion and distress-prone fetuses. Both sonographic findings (oligohydramnios and/or EFW $<3^{\text {rd }}$ centile) and the Doppler findings (increased UA PI or the decreased CPR) guided the clinician to take a decision on whether to induce labor (Table 2), resulting in $\leq 36 \mathrm{~h}$ followup time in $35.9 \%$ cases of $\geq 37$ weeks' gestation.

Female and male fetuses react differently to placental insufficiency. ${ }^{27,28}$ The present study reports strong evidence of more successful cerebral redistribution in male fetuses. Although the corporeal (the $\mathrm{AC}$ and $\mathrm{FL}$ ) \%DV was not different between the two genders, those of the cranial size parameters (\%DV BPD and HC) and the MCA PI were significantly higher in female fetuses. These findings are in accordance with those reported by Prior et al. who found reduced MCA indices in male fetuses and suggested that male fetuses utilized "centralization" more prominently than female fetuses. ${ }^{28}$

Two main limitations of this research were the retrospective design and the single operator methodology. In biometry and Doppler, the AC and the MCA, respectively, are very delicate measurements. For this reason, intra- and inter-observer variabilities should be studied and the data should be corrected for these factors. A prospective design would enable the elimination of such confounding factors, thereby drawing stronger conclusions on this issue.

\section{CONCLUSION}

The present study demonstrated that in FGR-suspected pregnancies, a single biometric measurement had a high sensitivity for detecting cases with NBW $<10^{\text {th }}$ centile. However, FGR is a diagnosis of surveillance; a suspect of FGR should be closely followed up in the light of the first Doppler findings obtained from three arterial fields. In FGR cases, the $\mathrm{CPR}<5^{\text {th }}$ centile finding could be useful in predicting fetal distress and NICU admission.

\section{Source of Finance}

During this study, no financial or spiritual support was received neither from any pharmaceutical company that has a direct connection with the research subject, nor from a company that provides or produces medical instruments and materials which may negatively affect the evaluation process of this study.

\section{Conflict of Interest}

No conflicts of interest between the authors and / or family members of the scientific and medical committee members or members of the potential conflicts of interest, counseling, expertise, working conditions, share holding and similar situations in any firm.

\section{Authorship Contributions}

This study is entirely author's own work and no other author contribution. 


\section{REFERENCES}

1. Smith-Bindman R, Chu PW, Ecker JL, Feldstein VA, Filly RA, Bacchetti P. US evaluation of fetal growth: prediction of neonatal outcomes. Radiology. 2002;223(1):153-61. [Crossref] [PubMed]

2. Hiersch L, Melamed N. Fetal growth velocity and body proportion in the assessment of growth. Am J Obstet Gynecol. 2018;218(2S): S700-11.e1. [Crossref] [PubMed]

3. Figueras F, Gratacos E. An integrated approach to fetal growth restriction. Best Pract Res Clin Obstet Gynaecol. 2017;38:48-58. [Crossref] [PubMed]

4. T.C. Sağlık Bakanlığı Türkiye Halk Sağlığı Kurumu. Doğum Öncesi Bakım Yönetim Rehberi. Yayın No: 924. Ankara: Sağlık Bakanlığı; 2014. p.44. [Link]

5. Nardozza LM, Caetano AC, Zamarian AC, Mazzola JB, Silva CP, Marçal VM, et al. Fetal growth restriction: current knowledge. Arch Gynecol Obstet. 2017;295(5):1061-77. [Crossref] [PubMed]

6. Deter RL, Lee W, Yeo L, Erez O, Ramamurthy $\mathrm{U}$, Naik M, et al. Individualized growth assessment: conceptual framework and practical implementation for the evaluation of fetal growth and neonatal growth outcome. Am J Obstet Gynecol. 2018;218(2S):S656-78. [Crossref] [PubMed] [PMC]

7. Bhide A, Acharya G, Bilardo CM, Brezinka $\mathrm{C}$, Cafici D, Hernandez-Andrade E, et al. ISUOG practice guidelines: use of Doppler ultrasonography in obstetrics. Ultrasound Obstet Gynecol. 2013;41(2):233-9. [Crossref] [PubMed]

8. Unterscheider J, Daly S, Geary MP, Kennelly MM, McAuliffe FM, O'Donoghue K, et al. Optimizing the definition of intrauterine growth restriction: the multicenter prospective PORTO Study. Am J Obstet Gynecol. 2013;208(4): 290.e1-6. [Crossref] [PubMed]

9. Gómez $O$, Figueras $F$, Fernández $S$, Bennasar M, Martínez JM, Puerto B, et al. Reference ranges for uterine artery mean pulsatility index at 11-41 weeks of gestation. UItrasound Obstet Gynecol. 2008;32(2):128-32. [Crossref] [PubMed] e109. [Crossref] [PubMed]
10. Acharya G, Wilsgaard T, Berntsen GK, Maltau JM, Kiserud T. Reference ranges for serial measurements of umbilical artery Doppler indices in the second half of pregnancy. Am J Obstet Gynecol. 2005;192(3): 937-44. [Crossref] [PubMed]

11. Ebbing C, Rasmussen S, Kiserud T. Middle cerebral artery blood flow velocities and pulsatility index and the cerebroplacental pulsatility ratio: longitudinal reference ranges and terms for serial measurements. Ultrasound Obstet Gynecol. 2007;30(3):287-96. [Crossref] [PubMed]

12. ACOG Practice Bulletin No. 204: Fetal Growth Restriction. Obstet Gynecol. 2019;133(2):e97-

13. Gordijn SJ, Beune IM, Thilaganathan B, Papageorghiou A, Baschat AA, Baker PN, et al. Consensus definition of fetal growth restriction: a Delphi procedure. Ultrasound Obstet Gynecol. 2016;48(3):333-9. [Crossref] [PubMed]

14. Turan OM, Turan S, Gungor S, Berg C, Moyano D, Gembruch U, et al. Progression of Doppler abnormalities in intrauterine growth restriction. Ultrasound Obstet Gynecol. 2008;32(2):160-7. [Crossref] [PubMed]

15. Grantz KL, Kim S, Grobman WA, Newman R, Owen J, Skupski D, et al. Fetal growth velocity: the NICHD fetal growth studies. Am J Obstet Gynecol. 2018;219(3):285.e1-285.e36. [Crossref] [PubMed]

16. Bertino E, Di Battista E, Bossi A, Pagliano M, Fabris $\mathrm{C}$, Aicardi $\mathrm{G}$, et al. Fetal growth velocity: kinetic, clinical, and biological aspects. Arch Dis Child Fetal Neonatal Ed. 1996;74(1):F10-5. [Crossref] [PubMed] [PMC]

17. Ott WJ. Sonographic diagnosis of fetal growth restriction. Clin Obstet Gynecol. 2006;49(2): 295-307. [Crossref] [PubMed]

18. Snijders RJ, Nicolaides KH. Fetal biometry at 14-40 weeks' gestation. Ultrasound Obstet Gynecol. 1994;4(1):34-48. [Crossref] [PubMed]

19. Chang TC, Robson SC, Boys RJ, Spencer JA. Prediction of the small for gestational age infant: which ultrasonic measurements best? Obstet Gynecol. 1992;80(6):1030-8. [PubMed]
20. McCowan LM, Figueras F, Anderson NH. Evidence-based national guidelines for the management of suspected fetal growth restriction: comparison, consensus, and controversy. Am J Obstet Gynecol. 2018;218(2S):S855-68. [Crossref] [PubMed]

21. Khalil A, Thilaganathan B. Role of uteroplacental and fetal Doppler in identifying fetal growth restriction at term. Best Pract Res Clin Obstet Gynaecol. 2017;38:38-47. [Crossref] [PubMed]

22. Oros D, Ruiz-Martinez $S$, Staines-Urias $E$, Conde-Agudelo A, Villar J, Fabre E, et al. Reference ranges for Doppler indices of umbilical and fetal middle cerebral arteries and cerebroplacental ratio: systematic review. Ultrasound Obstet Gynecol. 2019;53(4):454-64. [Crossref] [PubMed]

23. DeVore GR. The importance of the cerebroplacental ratio in the evaluation of fetal wellbeing in SGA and AGA fetuses. Am J Obstet Gynecol. 2015;213(1):5-15. [PubMed]

24. Figueras F, Gratacós E. Update on the diagnosis and classification of fetal growth restriction and proposal of a stage-based management protocol. Fetal Diagn Ther. 2014;36(2):86-98. [Crossref] [PubMed]

25. Morales-Roselló J, Khalil A, Morlando M, $\mathrm{Pa}$ pageorghiou $A$, Bhide $A$, Thilaganathan $B$. Changes in fetal Doppler indices as a marker of failure to reach growth potential at term. UItrasound Obstet Gynecol. 2014;43(3):303-10. [Crossref] [PubMed]

26. Baschat AA, Gembruch U. The cerebroplacental Doppler ratio revisited. Ultrasound $\mathrm{Ob}$ stet Gynecol. 2003;21(2):124-7. [Crossref] [PubMed]

27. Clifton VL. Review: sex and the human placenta: mediating differential strategies of fetal growth and survival. Placenta. 2010;31 Suppl:S33-9. [Crossref] [PubMed]

28. Prior $T$, Wild $M$, Mullins $E$, Bennett $P$, Kumar $S$. Sex specific differences in fetal middle cerebral artery and umbilical venous Doppler. PLoS One. 2013;8(2):e56933. [Crossref] [PubMed] [PMC] 